\title{
Erroneous GNSS Strain Rate Patterns and their Application to Investigate the Tectonic Credibility of GNSS Velocities
}

\author{
Andrzej ARASZKIEWICZ ${ }^{1}$, \\ Mariusz FIGURSKI ${ }^{1}$, and Marek JAROSIŃSKI ${ }^{2}$ \\ ${ }^{1}$ Military University of Technology, Faculty of Civil Engineering and Geodesy, \\ Warsaw, Poland; e-mail: andrzej.araszkiewicz@wat.edu.pl \\ ${ }^{2}$ Polish Geological Institute, Warsaw, Poland
}

\begin{abstract}
The paper concerns investigation of the credibility of tectonic interpretation of GNSS strain rates. The analysis was focused on stable regions, where the crustal deformations are small and the reliability of GNSS velocities is questionable. We are showing how the unreliable motion of stations affects calculated strains around them. We expressed distribution of local principal strains by a sinusoidal function and used them to investigate the significance of strain distortion. Then we used this method to investigate real motions of GNSS stations. As a test object we used Polish GNSS stations belonging to the ASG-EUPOS network. Station velocities were estimated on the basis of the 4.5 years of observations. The results let us identify stations that disturb the obtained local GNSS strain rate field. After verification and exclusion of some stations, the new GNSS strains show a much greater internal compatibility and also better fit to the directions of lithosphere stresses.
\end{abstract}

Key words: GNSS strain rates, GNSS velocities, reliability, Poland. 


\section{INTRODUCTION}

The potential of using GNSS measurements in the crustal deformation studies was noticed when the first such system, Navstar GPS, was created. Early works were related to active regions and tectonic faults, as the GPS accuracy was not high enough to show detailed movements of the Earth's crust in a wider range (Dermanis and Livieratos 1983). Today, thanks to development of GNSS technology, it is possible to detect displacement on the Earth's surface with an accuracy of less than $1 \mathrm{~cm}$. With long-term observations we are also able to determine the velocities of such movements even more precisely. Nowadays deformation studies based on GNSS measurements are conducted locally in practically all regions over the world. Researches are carried out even in Antarctica, where the GNSS measurements are used to determine the rate of deformation on ice shelft rifts (Janssen 2009). From the other side, GNSS stations are also used on a global scale. In work of Kreemer et al. (2014), the authors used velocities of over 20000 stations to develop a Global Strain Rate Model (GSRM v. 2.1). Following Altiner (2014), Segal (2010) or Allmendinger et al. (2014), the displacement $(u)$ of analysed body points $(x)$ in relation to its initial position $\left(x_{0}\right)$ can be written as

$$
u_{i}(x)=u_{i}\left(x_{0}\right)+\varepsilon_{i j} d x_{j}+\omega_{i j} d x_{j},
$$

where the first component $\left(u_{i}(x)\right)$ expresses motion of the rigid body (translation), while the remaining two represent its deformation (strain $\varepsilon$ and rotation $\omega$ ). In practice, when we use geodetic networks we must assume that the deformation of networks reflects the real movements of the Earth's crust and the area between geodetic points could be considered as a continuous medium. Only then we can interpret GNSS strain rates as real crust deformations. Generally, there are two approaches to estimate strains. We can invert the uniform velocity field to the strain rate field (Dermanis and Livieratos 1983, Altiner 2014, Allmendinger et al. 2007, Haines and Holt 1993) or calculate strain rates in triangular or more complex segments (Shen et al. 1996). Regardless of the used approach, we can express strains as eigenvalues for better presenting principal shortening and extension rates. Both methods have their supporters and opponents. Comparison of selected methods was done by $\mathrm{Wu}$ et al. (2011), where authors highlighted the respective advantages of each method. They found that Least-Squares Collocation (LSC) method (belonging to gridded approach), explained in details by Moritz (1972), is the best in most studied terms, like edge effect, error sensitivity or itself stability.

In our work we focused on Europe with special emphasis to Polish territory, which in other studies is often considered as a stable region. (e.g., Nocquet 2012). Nowadays, the number of GNSS stations in Poland exceeds 400; 
however, most of them are not dedicated to geodynamical research. In many cases their location and monumentation do not allow to interpret tectonic movements reliably. We have to keep in mind that in fact we observe antenna motion, not directly ground. Therefore, in order to observe crustal movements, all site self-motions should be excluded due to the fact that only with this approach the location of antennas could be interpreted as a real tectonic motion. Inappropriate located antenna may reflect structural motion (e.g., building) or near surface motions like superficial subsidence/collapse or slow motion landslides (Peyret et al. 2008, Wang 2012). To be sure that stations reflect the true motion, UNAVCO proposed precise monumentation connected to bedrock, like concrete pillars, metallic pillars, drilled braced tripods or steel masts. So far, it has not been proved that stations located on buildings or masts are worse than those sited directly on the solid rock. For many scientific and service purposes (e.g., reference frame, real-time measurement, ionosphere, and troposphere monitoring) such a monumentation is sufficient. In terms of tectonic research, movements of such stations should be interpreted with particular caution. In recent years, the establishment of stations on building roofs has become popular. This applies, in particular, to the reference stations for real-time surveying.

However, despite the fact that such networks are not dedicated to scientific research, they are a very valuable training ground for a variety of GNSS studies. An example of Polish territory, the GNSS meteorology (Bosy et al. 2012) or services for ionosphere state monitoring (Krypiak-Gregorczyk et al. 2013) can be mentioned. These works are based on the Polish network of reference stations called ASG-EUPOS (Bosy et al. 2008). This network, as well as many similar, was registered in the Research Infrastructure Database for EPOS (RIDE) as RI potentially usable for geoscience research on solid Earth in Europe. In most cases, stations are very well distributed, which allows to determine the full two-dimensional velocity field. Although Poland is not a tectonically active region, even here the studies of stress in the Earth's crust are conducted (Jarosiński 1998, 2006) and observations from geodetic networks can support and extend such a research (Bogusz et al. 2013b). However, it must be kept in mind that in case of GNSS measurements we can calculate only deformations of the geodetic network itself. Only with appropriate assumptions (arising from mechanics theory) we can interpret them as true crustal deformations. There is also no guarantee that velocities of such stations can be considered as reliable in terms of tectonic motions. In regions where crust deformations are small, errors and obscurity of calculated GPS strain rates, which in general are smaller and less reliable, are more visible. Even if the uncertainty of velocity's estimation is at a satisfactory level, it is still unclear how to interpret them correctly. The groundwork for any studies in the field of crust' deformations should be a proper 
verification and screening of the input data. In our case, they are related to velocity credibility without evaluating their quality itself due to the fact that even precisely estimated velocities can be just not reliable in the tectonic aspects. For this reason we decided to analyse how the erroneous velocities (within the meaning of their application to deformation studies) affect the determined local strain rates. In our studies we used segment approach, instead of the LSC method which is recognized as one of the best. We chose this method due to the fact that many of the works are still based on a segment (triangular) approach. An example might be the work of Deniz and Ozener (2010) or Araszkiewicz (2014), where authors, in order to avoid any distortion of the GPS network caused by datum itself, decided to use measured linear strain instead of station velocities. Similar methods are still often used by geodesists for local strain analysis (Szafarczyk et al. 2007) related to mine exploitation. As shown by Wu et al. (2011), this method is highly sensitive to input data errors, due to no redundancy in strain calculation. All discrepancies in the velocities directly affect the strain parameters. At the same time, this method is free from smoothing and filtering, which are the principles of the gridded methods. So we decided to use the biggest disadvantage of the segment approach in our analysis and switch it to its benefit.

\section{NUMERICAL SIMULATIONS}

Our research was dedicated to stable regions, where deformations are small and there are no significant faults that might have caused discontinuities of the investigated area. Such assumptions results from geological researches, which are showing that the general direction of present-day maximum stresses in Poland is N-S (Jarosiński et al. 2011). In this case, directions of the estimated GNSS strain rates should change smoothly and exhibit the same character. Our simulations were designed to demonstrate how an anomalous motion of station distorts a local strain rates which were computed on the basis of this stations. This part was based on specially designed micro-networks (Fig. 1) for which the individual stations were moved with the assumed velocity. For each network, we investigated the distortion caused by the movement of the central station (CS). The presented examples (Fig. 1) are related to the movement of CS in the NW direction $\left(A z^{S}=36^{\circ}\right)$ with linear velocity $\left(V_{L}^{S}\right)$ set to $0.5 \mathrm{~mm} / \mathrm{yr}$. In the test, surrounding motionless stations were spaced $30 \mathrm{~km}$ away from CS. Eigenvalues of the strain rate $\left(\varepsilon_{1}\right.$ - compression rate, $\varepsilon_{2}$ - extension rate) were calculated in triangular elements constructed on the basis of CS, as shown in Fig. 1. In our studies we used algorithm described by Cronin et al. (2014). In the analysed networks, the number of triangles depends directly on the number of surrounding stations: from 4 (Fig. 1A) up to 36 (Fig. 1H). 


\section{Simulated strain rates}
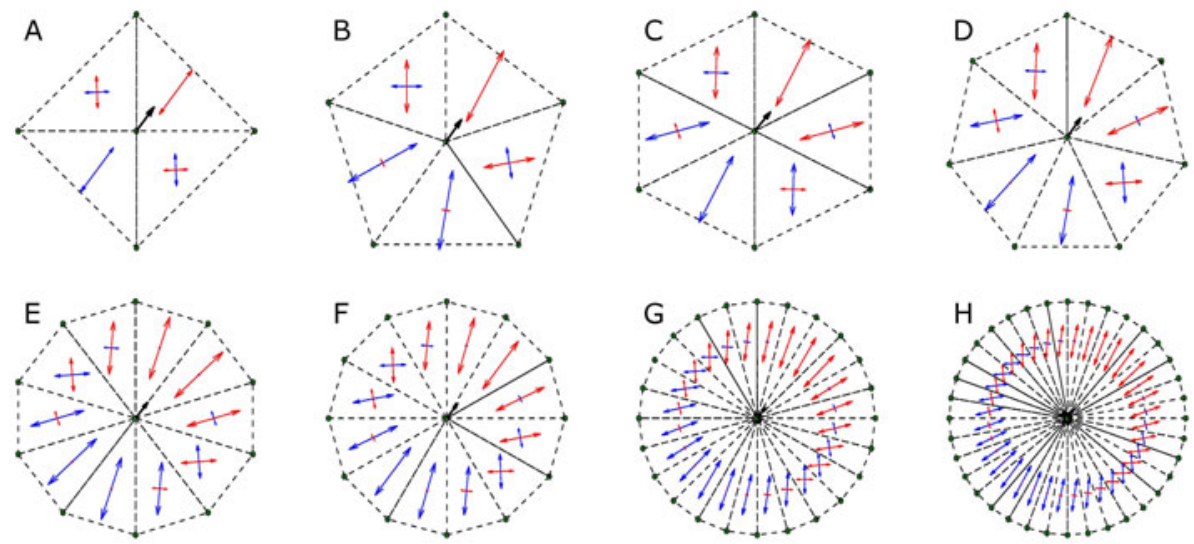

Fig. 1. GNSS strain rate distributions are induced by motion of the central station and stable group of surrounding stations. Eigenvalues of the strain rate tensors are presented as strain crosses (compression rate - red, extension rate - blue).

In such initial conditions, a motion of the CS caused a characteristic distribution of the rate of deformation. The maximum compression rate was obtained for triangles which were located in the NE direction from CS. In subsequent triangles (both clockwise and counter-clockwise direction) the compression rate gradually decreases to a minimum value in the SW direction. Opposite situation can be seen for the extension rate. We expressed such a distribution of strain rate values as a function of azimuth $(A z)$ from $\mathrm{CS}$ to the centre of each triangle (Fig. 2). Then we fitted the model function:

$$
\text { data }=F(A z)=A \cdot \sin (\omega) \cdot\left(A z-a_{0}\right)+s
$$

to this expression. The value of angular frequency was taken as a constant $(\omega=1)$, whereas the rest of the parameters $\left(A\right.$ - amplitude, $a_{0}$ - phase shift, $s$ - vertical shift) were estimated. We used eigenvalues of strain rate tensor and values of the first invariant (I1 $=\varepsilon_{1}+\varepsilon_{2}$ ), which is interpreted as the areal strain rate. In the studies we did not use the second invariant, because it tells us about magnitude of deformation without giving any information about its character. Initially we used three values (Fig. 2); however, in further work we focused only on first invariant of the strain rate tensor (I1), due to the fact that the results obtained based on them were the most rewarding. The obtained amplitude $(A)$ of sine wave demonstrates the strain rate field disturbance caused by the motion of CS. For the presented examples, this value is in the range from $16.73 \times 10^{-9} /$ year (Fig. $1 \mathrm{H}$ ) up to $23.57 \times 10^{-9} /$ year (Fig. 1A). 

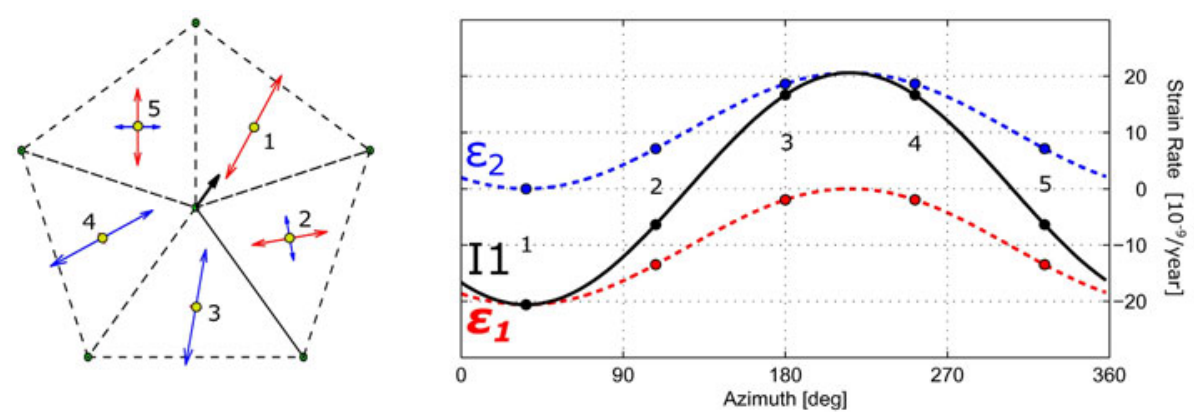

Fig. 2: Left: Distribution of the GNSS strain rates. Right: Points represent eigenvalues of strain rate tensor (red and blue) and its first invariant (black) calculated for each triangle. Lines present fitted sinewaves for each data.

However, this value is relative. It depends on the size and shape of the triangles, which differ significantly for presented cases $(\mathrm{A}-\mathrm{H})$. One can consider the situation in which the central station is moved perfectly in the colinear direction, with an azimuth of the line from CS to the centre of one of the triangles. This element will be under pure compressional rate $\left(\varepsilon_{1}\right)$ along $\theta=A z^{S}=36^{\circ}$, the extensional rate being negligible $\left(\varepsilon_{2}=0\right)$. Then, the estimated amplitude $\left(A_{\mathrm{II}}\right)$ corresponds to this compression rate. Using the formula for linear strain measured in any direction $\theta=90^{\circ}-A z$ (e.g., Segal 2010):

$$
\varepsilon_{\theta}=\varepsilon_{x x} \cos ^{2} \theta+\varepsilon_{y y} \sin ^{2} \theta+2 \varepsilon_{x y} \sin \theta \cos \theta
$$

we can prove that linear strain rate $\varepsilon_{\theta}$ is equal to principal strain rate $\varepsilon_{1}$ (since $\left.\varepsilon_{x x}=-70: 11, \varepsilon_{y y}=-13: 85, \varepsilon_{x y}=-9: 79\right)$. Based on the original height of such a triangle derived from CS $\left(l_{0}\right)$ and its linear strain rate $\left(\varepsilon_{l}=\varepsilon_{\theta}\right)$ we can calculate rate of change of its length. For this case it is equal to the velocity of CS as well.

$$
V_{L}^{O}=\partial u_{l 0}=\varepsilon_{\theta} \cdot l_{0}=A_{\mathrm{II}} \cdot l_{0} .
$$

For all simulated micro-networks, this value is exactly equal to simulated velocity $\left(V_{L}^{O}=V_{L}^{S}=0.5 \mathrm{~mm} /\right.$ year $)$, which confirms the above discussion. The phase shift of sine wave $\left(a_{0}\right)$ indicates a direction of the maximum compression rate and corresponds to the azimuth of the simulated velocity of CS $\left(a_{0}=A z\right)$. This was confirmed by numerical calculation conducted for the whole range of velocity directions (from 0 to $359^{\circ}$ ). Vertical shift $(s)$ corresponds to mean areal strain rate, which occurs in the area bounded by surrounding stations (without considering the motion of central station). In our studies, values of vertical shifts $(s)$ were on the level of fitting error (D) and can be considered as zero. Results of simulations are presented in Table 1. 
Sine wave parameters obtained in numerical simulations

\begin{tabular}{|c|c|c|c|c|c|c|}
\hline \multirow{2}{*}{$\begin{array}{c}\text { No. } \\
\text { stations }\end{array}$} & $A_{\mathrm{I} 1}$ & $l^{0}$ & $V_{L}{ }^{O}$ & $a_{0}$ & $s$ & $\mathrm{D}$ \\
\cline { 2 - 7 } & {$\left[10^{-9} /\right.$ year $]$} & {$[\mathrm{km}]$} & {$[\mathrm{mm} /$ year $]$} & {$\left[{ }^{\circ}\right]$} & {$\left[10^{-24} /\right.$ year $]$} & {$\left[10^{-24} /\right.$ year $]$} \\
\hline 4 & 23.57 & 21.21 & 0.5 & 36 & 1.60 & 0.44 \\
5 & 20.60 & 24.27 & 0.5 & 36 & 1.29 & 5.18 \\
6 & 19.24 & 25.98 & 0.5 & 36 & -4.68 & 16.52 \\
7 & 18.50 & 27.03 & 0.5 & 36 & -3.25 & 19.41 \\
10 & 17.52 & 28.52 & 0.5 & 36 & 1.85 & 13.84 \\
12 & 17.26 & 28.98 & 0.5 & 36 & 1.27 & 10.27 \\
24 & 16.81 & 29.74 & 0.5 & 36 & -1.23 & 29.23 \\
36 & 16.76 & 29.89 & 0.5 & 36 & 2.09 & 3.77 \\
\hline
\end{tabular}

Preliminary studies have shown that by using the decomposition of GPS strain rate around stations we can determine not only whether the station disturbs the local strain rate field or not, but also possible direction and magnitude of this motion in relation to the surrounding stations.

In practice, when we are using the GNSS networks we have to deal with more complicated situations. Usually each station moves a little and, therefore, our task is to determine when such movements disturb the local strain rate field significantly. The shape of the network is rarely uniform, as presented in Fig. 1. An exception may be only a specially designed network to monitor landslides or deformation caused by mining exploitation (e.g., Szafarczyk et al. 2007). Our further analyses increasingly differ from the ideal case and were supposed to be more realistic.

\subsection{Variant I}

Analyses for 5, 6 or 7 surrounding stations, as one of the most probable situations in the real life, were performed. In first modification, all surrounding stations were moved randomly. This part of analysis was marked as variant I. Figure 3 shows the results of 100 numerical simulations, in which velocities were set up to $0.25 \mathrm{~mm} /$ year (case A) and up to $0.50 \mathrm{~mm} /$ year (case B). The third case (C) refers to a situation where all stations, including central station, move randomly with velocities of $0-0.50 \mathrm{~mm} / \mathrm{year}$. For such modelled velocity, we calculated strain rate tensors and fitted sine waves, as described in the previous section. Results for both variants, IA and IB, were clear and satisfactory. We received the same pattern like in the "ideal case". The mean amplitude of the sine wave for the first invariant was, respectively, $A_{\mathrm{IA}}=20.9 \pm 3.64 \times 10^{-9} /$ year and $A_{\mathrm{IB}}=22.2 \pm 6.90 \times 10^{-9} /$ year. With 2 times increased movements of surrounding stations, the amplitude scatter was twice higher. 

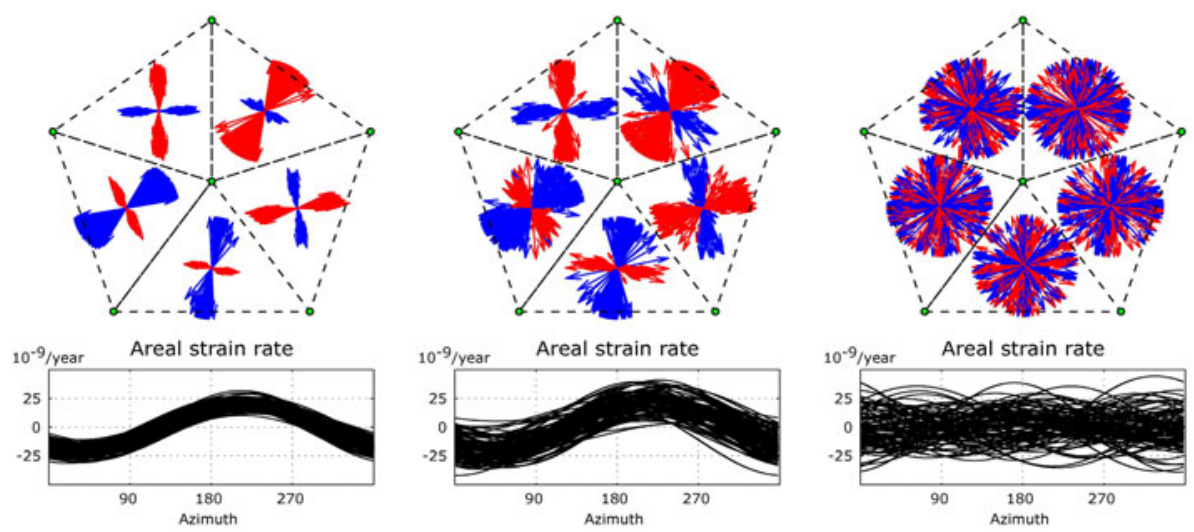

Fig. 3. Strain rate tensors calculated in mini-networks. Variants IA and IB with surrounding stations moving randomly, variant $\mathrm{C}$ with all stations (including central) moving randomly. Bottom charts present fitted sinewaves to I1 distribution for each of 100 simulations.

The obtained values of A indicate motion of the central station, with velocity at $0.51 \pm 0.08$ and $0.54 \pm 0.16 \mathrm{~mm} /$ year for these two cases. Additional simulations, with different velocity limit, showed that random velocities of surrounding stations up to $1.0 \mathrm{~mm} /$ year did not affect significantly the mean value of amplitude. However, the fitting error increased significantly. For the case in which velocities of surrounding stations were up to $1.0 \mathrm{~mm} /$ year, it reached $\pm 14.80 \times 10^{-9} /$ year.

\subsection{Variant II}

Similar simulations were carried out in further analyses (variant II). We included irregular shape of triangles, by changing distances to surrounding stations and their direction in relation to CS, in the range of $10 \mathrm{~km}$ and $15^{\circ}$, respectively (compared to their initial values used in variant I).

Velocities take values in the range of $0.0-0.1,0.0-0.2$, up to $0.0-$ $1.0 \mathrm{~mm} /$ year for cases IIA, IIB, up to IIJ. Motion of CS was fixed to $0.5 \mathrm{~mm} /$ year with azimuth $A=36^{\circ}$. Based on these assumptions we conducted 1000 strain simulations per each case, examples of which being presented in Fig. 4. Even for this variant, distribution of strain rates shows the same pattern, which allows to determine the anomalous movement of CS. The mean value of estimated amplitude varied in the range of 21.87 to $28.31 \times 10^{-9} /$ year, which for randomly generated networks corresponds to the velocity of central station in the range of 0.50 to $0.80 \mathrm{~mm} / \mathrm{year}$. For variant IIE, where the velocity limit was equal to the simulated velocity of central station, amplitude was $23.25 \times 10^{-9} /$ year with scattering of $\pm 8.142 \times 10^{-9} /$ year 

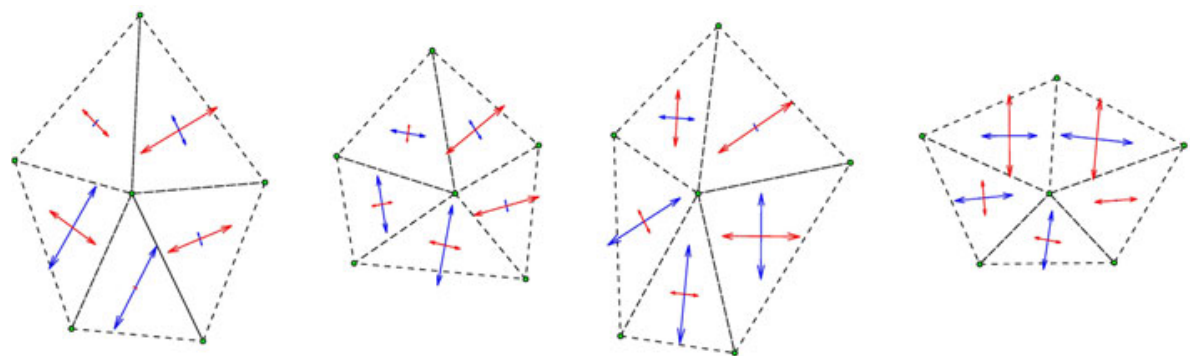

Fig. 4. Sample rosettes' shapes used in variant 2.
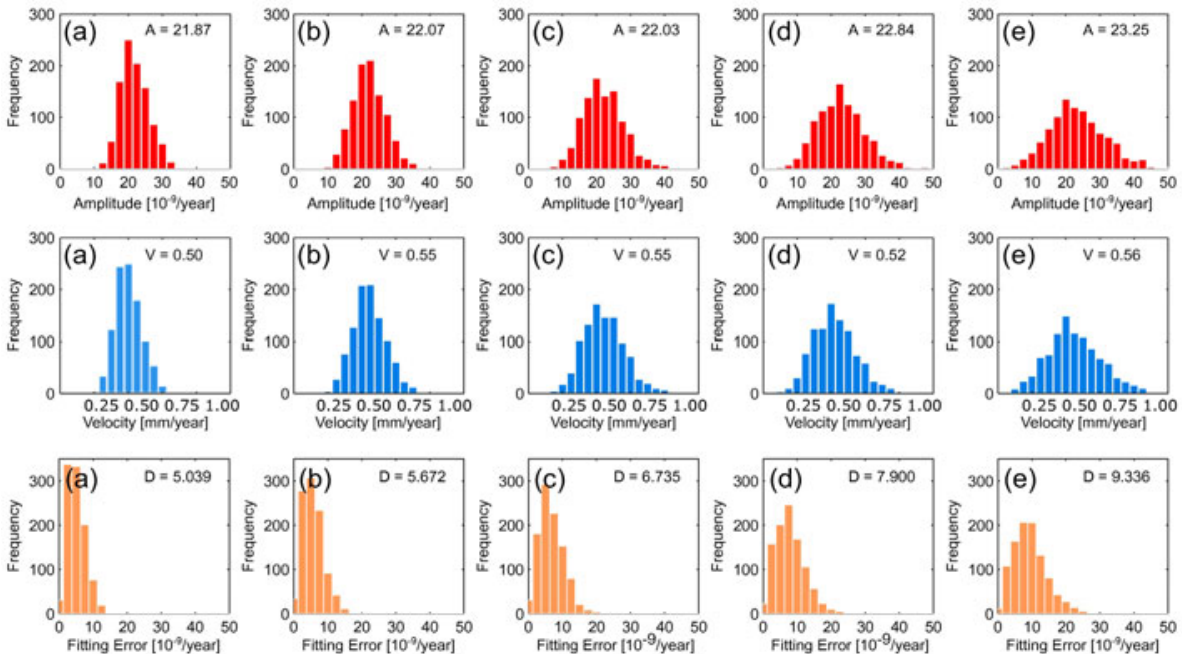

Fig. 5. Histograms of variant II results. Sine wave amplitude (red), estimated velocity of central station (blue), and fitting error (orange). Mean values of each parameter are displayed on each plot (A, V, and D, respectively).

which corresponds to the obtained velocity of CS at the level of $V_{L}{ }^{O}=$ $0.56 \pm 0.22 \mathrm{~mm} /$ year. Results for cases from (A) to (E) are presented in histograms in Fig. 5.

\section{REAL CASE: POLISH GNSS PERMANENT NETWORK}

Our simulations showed that anomalous motion of station lead to characteristic distribution of calculated strain rates. We are able to invert this situation and use this pattern to identify stations with an erroneous motion. As a test object we used Polish network of reference GNSS station called ASGEUPOS. It was created in 2008 by the decision of the Polish Head Office of Geodesy and Cartography (Bosy et al. 2008). The whole ASG-EUPOS net- 
work was already used in the geodynamical studies (Kontny and Bogusz 2012, Bogusz et al. 2013a), where authors focused on the development of a uniform velocity field using different methods of interpolations. In Bogusz et al. (2013b), authors also attempted to assess the credibility of estimated GNSS strain rates. They concluded that in general the obtained strain field is in a good agreement with the recent geological knowledge. However, they also indicated that the results do not reflect local variability of the deformation and are affected by the algorithms (mostly smoothing) which were applied. For this reason, this area requires further studies on the possibility of determining reliable strain rates from GNSS observations.

To estimate the station velocities we used 241 weeks of daily observations (GPS week 1466-1707) collected at 118 ASG-EUPOS stations. The GNSS processing was done according to Guidelines for the EPN Analysis Centres. We cumulated weekly solutions in CATREF software (Altamimi et al. 2003) and then estimated the velocities. Over 4.5 year period of observation is long enough to avoid the influence of the annual oscillation on the estimated velocities (Blewitt and Lavallée 2007). We decided to express the velocities in Eurasian plate (ETRF2000 reference frame) in order to eliminate the common motion. However, in analyses of the relative motion this should not really matter. Of little influence may only be the frame realization, as emphasized by Araszkiewicz et al. (2014). In our case, the relative motions between adjacent stations vary from 0.0 to $1.1 \mathrm{~mm} /$ year. With average distances between stations of $50 \mathrm{~km}$ this indicates strain rates of up to $30 \cdot 10^{-9} /$ year (in the extreme case it exceed $60 \times 10^{-9} /$ year). The aim of our studies was to identify the suspicious velocities, not to obtain a continuous strain field using GNSS data. In fact we wanted to determine the discontinuous strain rates (each segment is considered separately) and then check how continuous the resulted image of strains is. Then we used our method to identified velocities that cause the largest disturbances. Strain rate tensors were calculated independently for each segment, which in our case were triangles created according to the Delaunay method (Wessel and Smith 1998). For comparison, we calculated also strain rates using Least-Squares Collocation (LSC) method with two different correlation lengths: the one with correlation length equal to $50 \mathrm{~km}$, that should correspond to segment approach, and the other with the correlation length derived from the statistical analysis (approximately $150 \mathrm{~km}$ ). To estimate the covariance function, we used the Gaussian function that is frequently used in the geodynamic applications; it is available in GeoStrain software (Goudarzi et al. 2015). However, due to a large variety of velocities it was difficult to find proper parameters. This confirmed that the verification of the velocities is essential. For better comparison we estimated strains in the same way as it was defined in segment approach (triangle centres). 

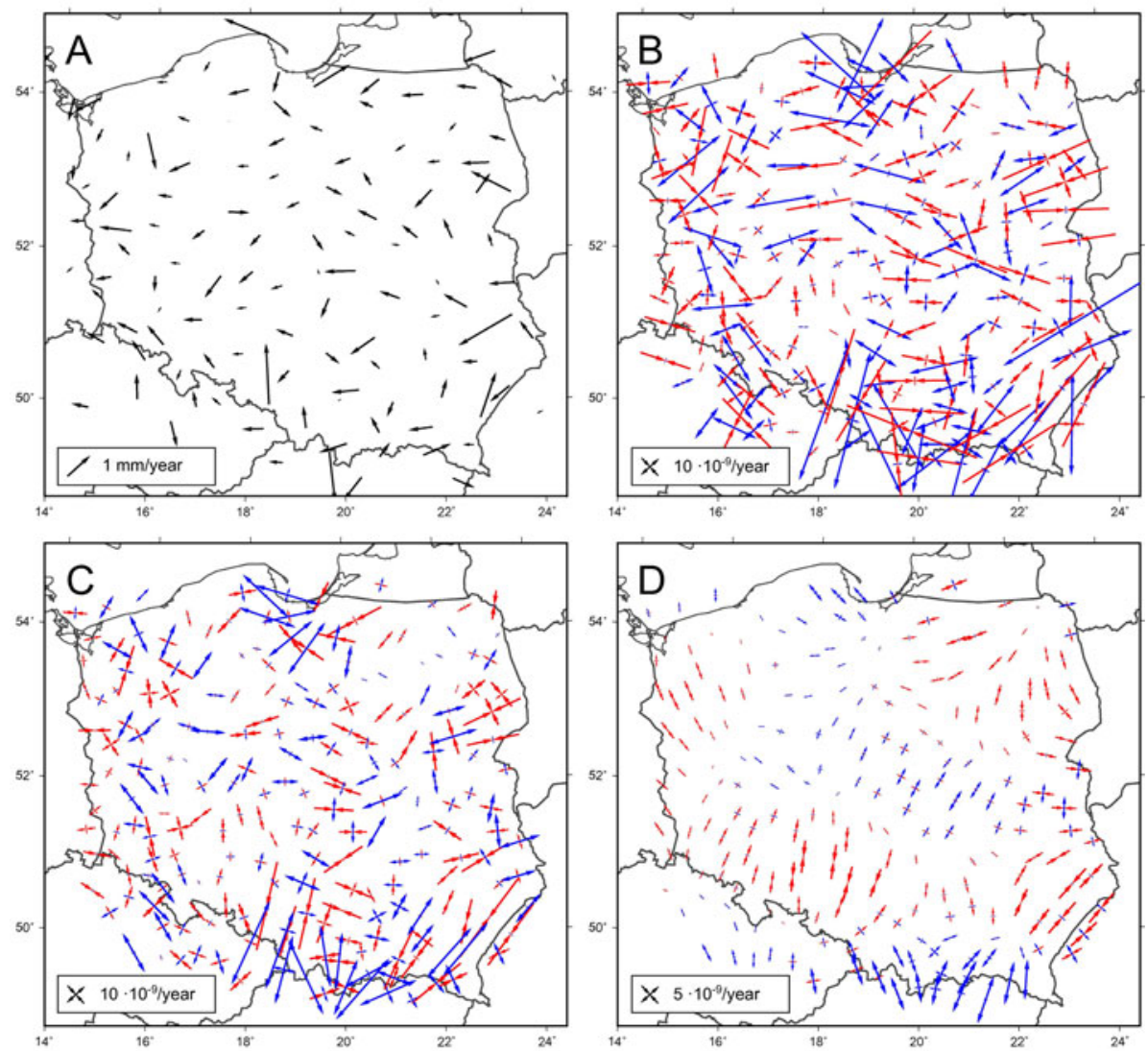

Fig. 6. GNSS strain rate tensors obtained using segment approach (B) and LSC method with different correlation lengths: $50 \mathrm{~km}(\mathrm{C})$ and $150 \mathrm{~km}$ (D). Input data (all estimated velocities) are presented on map A.

We also simplified our calculation and did not consider vertical motions. Results of the each method are presented in Fig. 6. We received a large inconsistency in strain rates tensors for both segment and LSC method (in case of correlation length equal to $50 \mathrm{~km}$ ). According to geological research (Jarosiński et al. 2011) we should get a dominant compression rate in the $\mathrm{N}$ $\mathrm{S}$ direction, which is better visible in the results of LSC method for the case of correlation length equal $150 \mathrm{~km}$. However, with higher value of adopted correlation length we smoothed the final field of strain rates but lost information about local discrepancies. It is good in terms of the final product but makes it impossible to investigate the velocities reliability. As it was indicated already by Bogusz et al. (2013b), strain rate tensors calculated on this network are not valid with respect to the expected crustal strains. Therefore, 
there is a suspicion that some of the stations used (or even all) show the local or self-motions. Based on our simulation we found that such stations can cause a large inconsistency in estimated strain rates around them. In such a case, we should receive characteristic pattern of strain rates (Figs. 1 and 3) and all tectonic interpretations based on these velocities may be inappropriate. Such patterns are clearly visible on Fig. 6B. It is still visible also on Fig. 6C, but slightly less due to the fact that the LSC method is more robust to such errors (Wu et al. 2011). We used the procedure described in the previous section to investigate strains around each station and look for a characteristic pattern (Fig. 7).

The highest value of the amplitude sine wave was obtained for station WODZ $\left(A=68.2 \times 10^{-9} /\right.$ year $)$ with a fitting error $\mathrm{D}=17.9 \times 10^{-9} /$ year. Based on the average distance to the neighbouring stations (equal to $46.4 \mathrm{~km}$ ), we are able to calculate how the velocity of this station deviates from the velocity field defined by surrounding stations. For station WODZ it is $3.3 \mathrm{~mm} /$ year in NNE direction $\left(A z=14^{\circ} .5\right)$. Among other stations we found the clearest pattern also for: $\operatorname{KROS}\left(A=43.3 \times 10^{-9} /\right.$ year, $\mathrm{D}=14.3 \times 10^{-9} /$ year $)$, LELO $\left(A=30.8 \times 10^{-9} /\right.$ year, $\mathrm{D}=13.2 \times 10^{-9} /$ year $)$, GNIE $\left(A=34.4 \times 10^{-9} /\right.$ year, $\mathrm{D}=12.5 \times 10^{-9} /$ year $)$ and BRSK $\left(A=35.8 \times 10^{-9} /\right.$ year, $\mathrm{D}=20.6 \times 10^{-9} /$ year $)$, as was shown in Fig. 7. Some of the identified stations are located directly next to each other. Due to this fact, there was a risk that the distortion caused by one of the station influenced to the wrong classification of neighbouring sta-

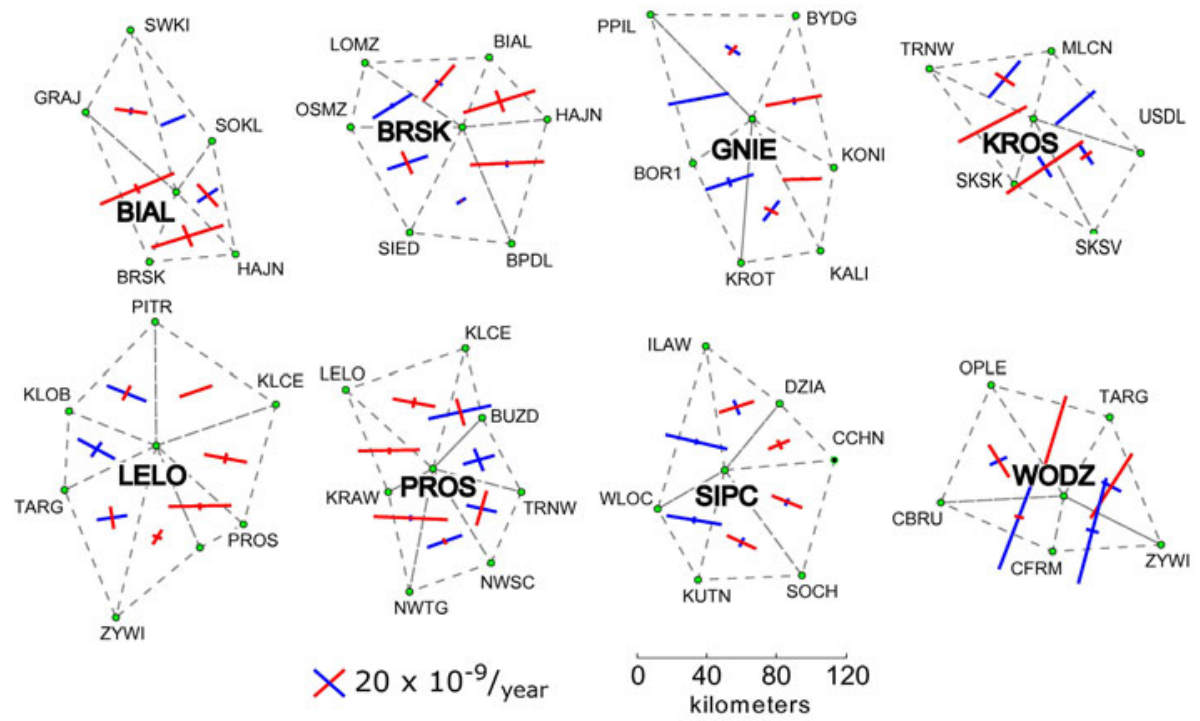

Fig. 7. Principal GNSS strain rates around selected stations. 

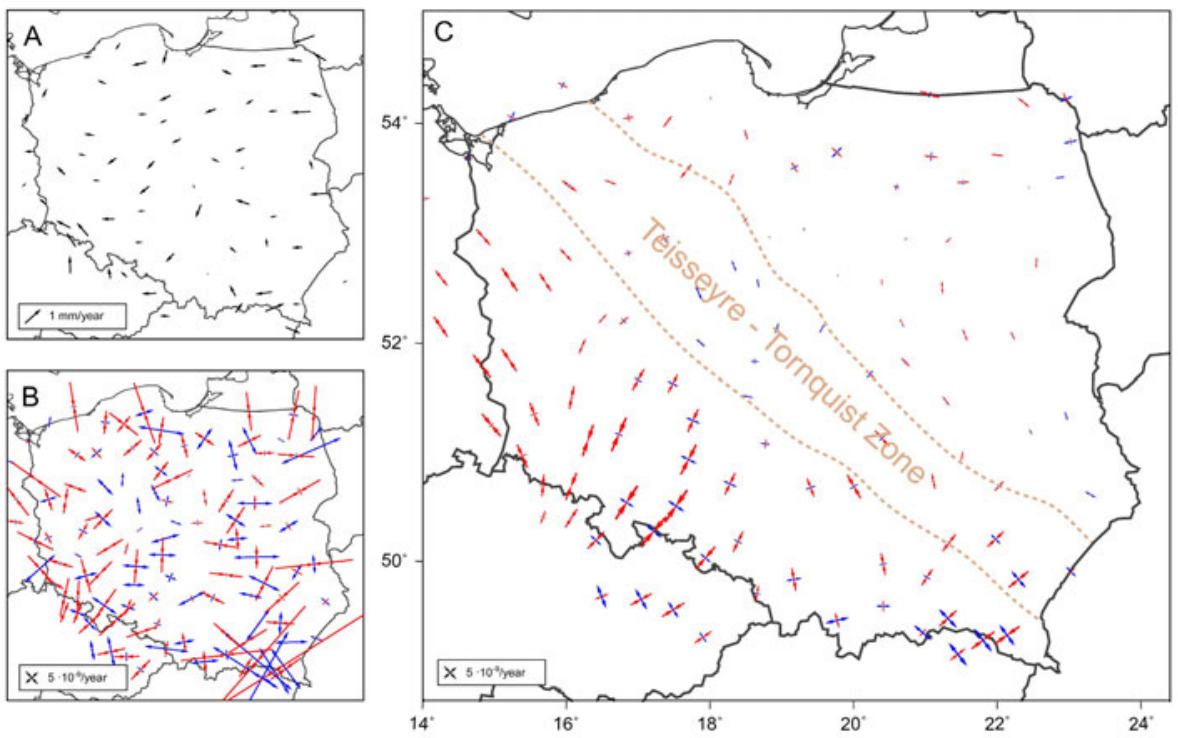

$14^{\circ}$ Fig. 8. Final GNSS strain rate tensors obtained using segment approach (B) and LSC
method (C). Correlation length for LSC was $150 \mathrm{~km}$. Input data (verified velocities) are presented on map A. In both methods, strain rates were estimated in the same points, determined by segment approach.

tions. Therefore, the entire procedure was carried out iteratively. First we identified the stations which causing the greatest disturbances, then we generated new triangles and run the procedure again. In our research we analysed the strain rates distribution as long as the method allowed to identify any station. At the end, all excluded stations were verified if they are still causing characteristic disturbances in the final GNSS data set. The entire identification was carried out in 6 steps, eliminating a total of 56 stations (this is almost $50 \%$ of all stations). Of course, not all identified velocities are critical, but we decided to identify all of them. For comparison, in Bogusz et al. (2013b) authors assumed that for Polish territory, which is a tectonically stable area, strain rates should not exceed $5 \times 10^{-9} /$ year. They eliminated 26 stations that cause such strains and then determined a final image of strains. 25 of them were also identified by our method (one of them is located at the edge of the network, so we could not test them correctly).

Finally, basing on verified data set, we calculated again GNSS strain rates tensors, using segment approach. The sparseness of the data is now much worse, but still over 50 stations were used. The new strains show a much better consistency between surrounding segments (Fig. 8B). Only in central part of the area of Poland we still notice some discrepancies. How- 
ever, when we estimated strains using LSC method, the received image of the strain rates is much better.

Directions of main strain axes obtained by using our method (Fig. 8C) are much more stable, and changes are more gradual than in the case of those calculated from raw data (Fig. 6D). They show also striking similarity to the present-day horizontal stress directions (Jarosiński et al. 2006). Similarly, Fig. 6D shows a significant dominance of the elongation rate (extension rate) over the shortening rate (contraction rate) in several regions of Poland, including the Carpathians, the part of central Poland and Pomerania. Occurrence of the elongation rate in these areas is not justified by any kind of geological data, which points to strike-slip stress regime and dominance of shortening over extension in specified regions (Jarosiński 2005, 2006), which is in agreement with our results shown in Fig. 8C. Also strain rates in Fig. $8 \mathrm{C}$ are more comprehensive due to use of filtration. More precisely, southern and southwestern part of Poland is deformed more intensively than the northeastern area. These results agree well with intensity of historic and recent seismic activity (and seismic hazard), with their maximum in the Sudetes and the Carpathians and almost vanishing activity in northeastern Poland (Guterch 2009, 2015).

\section{SUMMARY}

The aim of presented studies was to demonstrate how to investigate and filter GNSS strain rates estimated in the stable regions. In our analysis we used segment approach, which is very sensitive to spatial distribution of the data points (Wu et al. 2011). In this method, any errors of the velocity are directly reflected on estimated strain rates. We used this fact to verify the velocity of each station.

We proposed how to analyse the GNSS strain rates calculated in triangular elements to detect interfering stations. We have shown that stations which have anomalous movement generate a characteristic pattern in local strain rates field. This pattern can be described in mathematical form (we propose sinusoidal function) and can be used to verify whether the individual velocity significantly disturbs a local strain rate field or not. In our study we assumed that neighbouring stations should show a similar motion. This assumption is true only in areas where crustal deformations are relatively homogeneous and continuous. The method is therefore not universal and we propose to use in the stable region. The method also requires a uniform distribution of the data input, because the segment approach that we used is very sensitive to data sparseness. We applied it to the Polish GNSS network called ASG-EUPOS. The initial density of the velocity is suitable for our method. We identified a total of 56 stations, which show differences in the direction of the motion in relation to neighbouring stations. This may indi- 
cate their unreliable velocities. The rest of stations have velocities that are consistent enough not to cause the characteristic distribution of strain rates.

The area of Poland is a stable part of Europe, and the usage of GNSS measurements from existing networks to analyse Earth's crust deformation is still questionable. We cannot forget that in fact we calculate the deformation of GNSS network and such verification is necessary for the proper interpretation. However, we showed that appropriate filtering significantly improves the final image of the strain rates. In Fig. $8 \mathrm{C}$ we present the strain rate field estimated using LSC method after station verification. These results are much more consistent with the present-day horizontal stress directions (e.g., Jarosiński et al. 2006) than the results before verification (Fig. 6D). The conducted verification whether the existing GNSS stations represents the current tectonic motion reliably may indicate also the locations for new stations. It is especially important for institutions that plan to establish new stations dedicated to monitor tectonic motion (e.g., in the EPOS Framework) and definitively verify the results received so far.

Acknowledgments. The research was founded by the National Science Centre of Poland (decision No. DEC-2013/09/N/ST10/03569). The GNSS processing was performed on the cluster computer with HP Proliant DL380 servers belonging to Centre of Applied Geomatics at the Faculty of Civil Engineering and Geodesy, Military University of Technology. The analyses were carried out in cooperation with the HOGC (Head Office of Geodesy and Cartography in Poland) concerning ASG-EUPOS monitoring and providing QC of the observations. The Generic Mapping Tools (Wessel and Smith 1998) and Inkscape software ware used for preparing all figures in this paper.

\section{References}

Allmendinger, R.W., R. Reilinger, and R. Loveless (2007), Strain and rotation rate from GPS in Tibet, Anatolia, and the Altiplano, Tectonics 26, 3, DOI: 10.1029/2006TC002030.

Allmendinger, R.W., N. Cardozo, and D.M. Fisher (2014), Structural Geology Algorithms: Vectors and Tensors, Cambridge University Press, Cambridge, DOI: $10.1017 / \mathrm{CBO} 9780511920202$.

Altamimi, Z., P. Sillard, and C. Boucher (2003), CATREF Software: Combination and Analysis of Terrestrial Reference Frames, Publication of Laboratoire de Rechereche en Géodésie, Institut Géographique National. 
Altiner, Y. (2014), Analytical Surface Deformation Theory for Detection of the Earth's Crust Movements, Springer, Berlin Heidelberg.

Araszkiewicz, A. (2014), Strain gauge rosettes constructed on the extensive gps network and its application in geodynamical research. In: Proc. 14th Int. Multidisciplinary Scientific GeoConference SGEM, 19-25 June 2014, Book 2, Vol. 2, 473-480, DOI: 10.5593/SGEM2014/B22/S9.059.

Araszkiewicz, A., K. Szafranek, and M. Figurski (2014), Reference frame realization impact on network deformation - geodynamic research in tectonic stable areas. In: Proc. 14th Int. Multidisciplinary Scientific GeoConference SGEM, 19-25 June 2014, Book 2, Vol. 2, 427-434, DOI: 10.5593/ SGEM2014/B22/S9.054.

Blewitt, G., and D. Lavallée (2007), Effect of annual signals on geodetic velocity, J. Geophys. Res. 107, B7, 2145, DOI: 10.1029/2001JB000570.

Bogusz, J., A. Klos, P. Grzempowski, and B. Kontny (2013a), Modelling the velocity field in a regular grid in the area of Poland on the basis of the velocities of European permanent stations, Pure Appl. Geophys. 171, 6, 809-833, DOI: $10.1007 / \mathrm{s} 00024-013-0645-2$.

Bogusz, J., A. Klos, M. Figurski, M. Jarosinski, and B. Kontny (2013b), Investigation of the reliability of local strain analysis by the triangle modelling, Acta Geodyn. Geomat. 10, 3, 293-305, DOI: 10.13168/ AGG.2013.0029.

Bosy, J., A. Oruba, W. Graszka, and M. Leonczyk, and M. Ryczywolski (2008), ASG-EUPOS densification of EUREF permanent network on the territory of Poland, Rep. Geod. 2, 85, 105-112.

Bosy, J., J. Kaplon, W. Rohm, J. Sierny, and T. Hadas (2012), Near real-time estimation of water vapour in the troposphere using ground GNSS and the meteorological data, Ann. Geophys. 30, 9, 1379-1391, DOI: 10.5194/angeo30-1379-2012.

Cronin, V., S. Olds, B. Pratt-Sitaula, and N. West (2014), Infinitesimal strain analysis using GPS data: Module for structural geology or geophysics course, UNAVCO, Boulder, USA, available from: http://www.unavco.org/ education/resources/educationalresources/lesson/majors-gps-strain/majorsgps-strain.html.

Deniz, I., and H. Ozener (2010), Estimation of strain accumulation of densification network in Northern Marmara Region, Turkey, Nat. Hazards Earth Syst. Sci. 10, 10, 2135-2143, DOI: 10.5194/nhess-10-2135-290 2010.

Dermanis, A., and E. Livieratos (1983), Applications of deformation analysis in geodesy and geodynamics, Rev. Geophys. Space Phys. 21, 1, 41-50, DOI: 10.1029/RG021i001p00041.

Goudarzi, M.A., M. Cocard, and R. Santerre (2015), GeoStrain: An open source software for calculating crustal strain rates, Comput. Geosci. 82, 1-12, DOI: 10.1016/j.cageo.2015.05.007.

Guterch, B. (2009), Seismicity in Poland in the light of historical records, Geol. Q. 57, 513-520. 
Guterch, B. (2015), Seismicity in Poland: Updated seismic catalog. In: B. Guterch and J. Kozak (eds.), Studies of Historical Earthquakes in Southern Poland, GeoPlanet: Earth and Planetary Sciences, Springer, 75-101, DOI 10.1007/ 978-3-319-15446-6_3.

Haines, A., and W. Holt (1993), A procedure for obtaining the complete horizontal motions within zones of distributed deformation from the inversion of strain-rate data, J. Geophys. Res. 98, B7, 12057-12082, DOI: 10.1029/ 93JB00892.

Janssen, V. (2009), Horizontal strain rate distribution on an active ice shelf rift from in-situ GPS data, J. GPS 8, 6-16, DOI: 10.5081/jgps.8.1.6.

Jarosiński, M. (1998), Contemporary stress field distortion in the Polish part of the Western Outer Carpathians and their basement, Tectonophysics 297, 1-4, 91-119, DOI: 10.1016/S0040-1951(98)00165-6.

Jarosiński, M. (2005), Ongoing tectonic reactivation of the Outer Carpathians and its impact on the foreland: Results of borehole breakout measurements in Poland, Tectonophysics 410, 189-216.

Jarosiński, M. (2006), Recent tectonic stress field investigations in Poland: a state of the art, Geol. Q. 50, 303-321.

Jarosiński, M., F. Beekman, G. Bada, and S. Cloetingh (2006), Redistribution of recent collision push and ridge push in Central Europe: insights from FEM modelling, Geophys. J. Int. 167, 860-880.

Jarosiński, M., F. Beekman, L. Matenco, and S. Cloetingh (2011), Mechanics of basin inversion: Finite element modelling of the Pannonian Basin System, Tectonophysics 502, 1-2, 121-145, DOI: 10.1016/j.tecto.2009.09.015, 300.

Kontny, B., and J. Bogusz (2012), Models of vertical movements of the Earth crust surface in the area of Poland derived from leveling and GNSS data, Acta Geodyn. Geomat. 9, 3, 331-337.

Kreemer, C., G. Blewitt, and E.C. Klein (2014), A geodetic plate motion and global strain rate model, Geochem. Geophys. Geosys. 15, 10, 3849-3889, DOI: 10.1002/2014GC005407.

Krypiak-Gregorczyk, A., P. Wialgosz. D. Gosciewski, and J. Paziewski (2013), Validation of approximation techniques for local total electroncontent mapping, Acta Geodyn. Geomat. 10, 3, 275-283, DOI: 10.13168/AGG.2013. 0027.

Moritz, H. (1972), Advanced Least-squares Methods, Ohio State University, Columbus, USA.

Nocquet, J.-M. (2012), Present-day kinematics of the Mediterranean: A comprehensive overview of GPS results, Tectonophysics 579, 220-242, DOI: 10.1016/j.tecto.2012.03.037.

Peyret, M., Y. Djamour, M. Rizza, J. Ritz, J. Hurtrez, M. Goudarzi, H. Nankali, J. Chery, K. Le Dortz, and F. Uri (2008), Monitoring of the large slow Kahrod landslide in Alboz mountain range (Iran) by GPS and SAR inter- 
ferometry, Eng. Geol. 100, 3-4, 131-141, DOI: 10.1016/j.enggeo.2008.02. 013.

Segal, P. (2010), Earthquake and Volcano Deformation, Princeton University Press.

Shen, Z., D. Jackson, and B. Ge (1996), Crustal deformation across and beyond the Los Angeles basin from geodetic measurements, J. Geophys. Res. 101, B12, 27957-27980, DOI: 10.1029/96JB02544.

Szafarczyk, A., M. Ulmaniec, and W. Borowiec (2007), An attempt to apply tensor calculus to evaluate the deformation condition of vertical upper embankment zones for a landfill located in a mining area, based on satellite measurement results, Rep. Geodesy 82, 317-326.

Wang, G. (2012), Kinematics of the Cerca del Cielo, Puerto Rico landslide derived from GPS observations, Landslides 9, 1, 117-130, DOI: 10.1007/s10346011-0277-5.

Wessel, P., and W.H. Smith (1998), New, improved version of generic mapping tools released, Eos Trans. 79, 47, 579, DOI: 10.1029/98EO00426.

Wu, Y., Z. Jiang, G. Yang, W. Wei, and X. Liu (2011), Comparison of GPS strain rate computing methods and their reliability, Geophys. J. Int. 185, 2, 703717, DOI: 10.1111/j.1365-246X.2011.04976.x.

Received 11 June 2015

Received in revised form 10 December 2015

Accepted 29 December 2015 